\title{
Regenerative Epithelium Present
}

National Cancer Institute

\section{Source}

National Cancer Institute. Regenerative Epithelium Present. NCI Thesaurus. Code C82992.

A morphologic finding indicating epithelial regrowth following injury. 